They should be reassured that if a severe adverse reaction occurs it will quickly disappear if the drug is stopped.

At first, close supervision is necessary, and patients often require encouragement to persevere with treatment during the several months that may elapse before real benefit accrues. After the maximum tolerated dose has been reached it may be redistributed in the 24 hours to obtain optimal benefit throughout the day, and minor adjustments may be required from time to time. Even patients who show a sustained improvement on levodopa may notice a fluctuation in their functional ability from day to day. ${ }^{8}$ Once a patient has become familiar with his treatment he need be seen only infrequently, and it is reasonable to prescribe at least one month's supply of drugs at each attendance.

British Medical fournal, 1970, 1, 446.

2 British Medical fournal, 1970, 4, 478 and 541.

3 Hunter, K. R., Stern, G. M., and Sharkey, J., Lancet, 1970, 2, 1366.

Hughes, R. C., Polgar, J. G., Weightman, D., and Walton, J. N., British Medical fournal, 1971, 1, 7 .

Yaryura-Tobias, J. A., Wolpert, A., Dana, L., and Merlis, S., Diseases of the Nervous System, 1970, 31, 60.

Hunter, K. R., Stern, G. M., and Laurence, D. R., Lancet, 1970, 2, 1283.

Mawdsley, C., British Medical fournal, 1970, 1, 331.

Barbeau, A., Canadian Medical Association fournal, 1969, 101, 791.

\section{Short-leg Syndrome}

When faced with otherwise unexplained musculoskeletal symptoms the clinician may be tempted to postulate mechanical stresses associated with asymmetry of the limbs or limbgirdles. There have been several studies of unequal length of legs and pain low in the back. Techniques have included intricate measurements on radiographs taken in the erect position, measurement of true and apparent leg-length by tape measure, and simple palpation of the iliac crests while correcting pelvic tilt with heel blocks of different heights. The results suggest that the last method is quite adequate for routine clinical practice. From $x$-ray measurements W. A. Rush and H. A. Steiner ${ }^{1}$ found that $77 \%$ of 1,000 soldiers with low back pain had an average inequality of leg-length of $7 \mathrm{~mm}$. Similarly A. Stoddard ${ }^{2}$ found that 17 of 100 patients had 0.5 in $(12.5 \mathrm{~mm})$ or more ot femoral shortening compared with $8 \%$ of symptomless control subjects. P. J. R. Nichols and N. T. J. Bailey ${ }^{3}$ studied the observer-error in measurement of the apparent length of the legs by tape measure from the anterior superior iliac spines to the medial malleoli and concluded that differences of 0.5 in $(12.5 \mathrm{~mm})$ or more were diagnostically significant. Using this method, Nichols $^{4}$ found leg shortening in $22 \%$ of 180 airmen with back ache compared with only $7 \%$ of controls. B. J. Sicuranza and his colleagues ${ }^{5}$ screened 1,000 obstetric patients by palpating the iliac crests and found $63(6 \%)$ with unequal legs. Of these 53 complained of either low back or flank pain for which no gynaecological cause was evident. They claimed that $90 \%$ of these patients were relieved by compensatory heel raises.

Simple developmental inequality of length of the legs is usually not gross. The patient stands with a slight pelvic tilt, and there is commonly a compensatory thoraco-lumbar scoliosis. There may be some asymmetry of the height of the shoulders-which may well have been noted previously by an observant tailor. On the short side the flank will appear less hollow, the hip less prominent, and the gluteal fold lower. Many years may elapse before symptoms develop. Presumably the younger mobile spine is capable of adapting to unequal mechanical stresses.

More extreme cases may be due to congenital or acquired hip disease, while growth of the bones may be retarded by poliomyelitis and accentuated by chronic osteomyelitis and vascular malformations. Some degree of shortening is common after major fractures of the lower limb, and compensation is essential if the patient is to walk without a limp; an ill-fitting leg prosthesis can produce similar effects. In such cases the knee joint of the longre leg may be kept flexed to compensate. A. St. J. Dixon and S. Campbell-Smith ${ }^{6}$ have shown that in patients with real or apparent inequality of leg-length of more than $25 \mathrm{~mm}$ present for more than one year the knee joint on the longer side was subject to greater arthritic damage.

It seems, then, desirable to treat any inequality in the length of the legs of more than $12.5 \mathrm{~mm}$ even if it is not currently causing symptoms. If the deformity is longstanding correction should be performed in stages. Adjustments of up to $25 \mathrm{~mm}$ can be made simply by raising one heel and lowering the other. If, however, a raise of more than $12.5 \mathrm{~mm}$ is required on one side some thickening of the sole is necessary.

${ }^{1}$ Rush, W. A., and Steiner, H. A., American fournal of Roentgenology and Radium Therapy, 1946, 56, 616.

'Stoddard, A., in Proceedings of the International Congress of Physical Medicine, p. 260. London, Headley, 1955

${ }^{3}$ Nichols, P. J. R., and Bailey, N. T. J., British Medical fournal, 1955, 2, 1247 .

${ }^{4}$ Nichols, P. J. R., British Medical fournal, 1960, 1, 1863.

sicuranza, B. J., Richards, J., and Tisdall, L. H., American fournal of Obstetrics and Gynecology, 1970, 107, 217.

Dixon, A. St. J., and Campbell-Smith, S., Annals of the Rheumatic Diseases, $1969,28,359$.

\section{A Psychiatrist in Space?}

Four hundred and fifty years ago Ferdinand Magellan entered the Mar Pacifico by the straits that now bear his name. He was on a voyage to circumnavigate the world, and he called on his priest to bless the ships, led his crew in chanting a Te Deum, and fired off his guns. No doubt this ceremony gave comfort to the explorers of the sixteenth century, but from where can the astronauts of the twentieth century draw sustenance when they pass through their Straits of Magellan?

With the advent of another journey to the moon one cannot help but think of Apollo 13. It was during this mission that the mental reserves of three men were tested, perhaps, to the limit, and yet they came through the ordeal without the need for spiritual or psychological support provided by a third party. Their only contact with civilization was what may have seemed to be the impersonal voice of mission control supplying technical information in a stereotyped manner.

Do the astronauts need a psychiatrist? The aerospace world is divided-though not equally. The vast majority of aerospace doctors can see no role for the specialist in psychological medicine during a space flight. They argue that astronauts are essentially self-selecting individuals whose experience and skill in aviation fit them for their role and whose ability to complete the training programme excludes the possibility that they may not be able to cope under pressure. The very few who can see a part for the psychiatrist argue the need for a person able to understand their difficulties and advise them in their time of need. The astronauts claim to feel a personal relationship with mission control and have not considered the need for a doctor trained in psychological medicine. ${ }^{1}$ It would appear that the voice of mission control and the skill and experience which it represents is their support. 
The exclusion of psychiatry from space medicine raises wider issues. Can psychiatrists by the nature of their training and experience ever be of help under such circumstances? Or, to put it another way, what has been their contribution to preventive medicine in this age of stress? It would appear that the voice of mission control was psychotherapy itself, and perhaps the psychiatrists can tell us what is so special about psychotherapy from a doctor.

1 Aldrin, E., unpublished communication, 1971.

\section{Return to Kindersley}

Like travellers returning to a once-familiar landscape the Gentral Medical Services Committee and the Central Committee for Hospital Medical Services explored the territory mapped out in Sir Keith Joseph's recent letter about the new Review Body (see Supplement, pp. 28, 30, and 33). Despite the political earthquake which so effectively destroyed the Kindersley Review Body in June last year, the new landscape was surprisingly familiar. Indeed, so much seemed to be as before that the committees were inclined to search for hidden obstacles in the most innocent looking byways.

This was understandable-and necessary-for what happened last summer damaged doctors' confidence. In the event, the Secretary of State's letter is a substantial advance for the profession on the proposals which the new Government had put to the B.M.A. at earlier meetings on the proposed review machinery. ${ }^{1}$ The letter is comprehensive, as Sir Keith wishes to avoid misunderstandings in the future over interpretation of the Government's intentions.

The ground rules of Pilkington are unchanged. ${ }^{2}$ The Review Body is to be given freedom on the timing of reviews and its sources of evidence. It can look at all the factors it considers relevant, taking into account "movement of earnings in other professions"-though the 11-year-old Pilkington relativities with them are now set aside - and "the quality and quantity of recruitment in all professions." The Government declares its own concern about manpower, emigration trends, and work load. The mechanics of the review will be altered. In place of a Cabinet Office secretariat which serviced Kindersley there will be one provided by the Office of Manpower Economics-despite objections by the Association, which feared it was a reincarnated P.I.B. This office will service not only the doctors' and dentists' Review Body but also the other two review bodies, ${ }^{3}$ and will be subordinate to them all. There are to be separate chairmen, however, and a minimum of cross-representation between the three bodies.

The Government and the professions will be free to reject, and the Government to modify, the conclusions of any particular report, but the Government regards it as impracticable to define in advance its own likely "compelling reasons" for so doing. The profession feels strongly that for the Government to interfere with the recommendations, having already given evidence at a particular review, which must include its views on the general economic situation, is taking a double bite at the cherry. Whether the forthcoming Industrial Relations Act will provide a means of holding future Governments to the Review Body's advice is not known at present, but the B.M.A. will want to explore this possibility. ${ }^{4}$
Some junior doctors may well be unhappy about the Government writing into this document its views about the timing of the next award for training grades. However, the Secretary of State has conceded the B.M.A.'s view that the Review Body must have complete freedom of action, with the doctors and the Department equally free to present whatever evidence they wish for the forthcoming review. Statistical evidence will be agreed as before in a joint technical working group. Both sides can then make their own interpretation.

The omission of a limit on the period between reviews will worry some doctors. The Royal Commission left this decision to the Review Body, but the increasingly uncertain economic situation gives justification for more frequent reviews than previously. There is no indication of the size or membership of the new Review Body, but the Kindersley arrangements make a good precedent and they commanded the profession's confidence.

While it is too much to expect that Governments will never play politics with the recommendations, at least the extent to which they can do so over the timing of the announcement should be curtailed. Some of the later reports from Kindersley suffered long delays between presentation to the Prime Minister and publication. Such a delay precipitated the clash between doctors and the previous administration last year. Obviously the Government must have time to consider any proposals thoroughly, but agreement on a time limit in future would lessen the scope for dispute.

The Secretary of State has not met B.M.A. requests that the pay of public health medical officers and N.H.S. doctors' superannuation should be included in the Review Body's remit. But further talks are to be held, and while Sir Keith may look forward to Health Service integration as mitigating the public health doctors' troubles he should consider the case for improving their plight beforehand. The Department is also in danger of underestimating the strength of feeling in the profession against the present superannuation scheme. Doctors will not readily be brushed aside on this issue.

The outcome of the discussions between Sir Keith Joseph and the B.M.A. on the Review Body is better than had been expected. This is just as well. The economic situation has become even more uncertain since the summer, and though not an impregnable defence against inflation-or political manoeuvrings - an independent Review Body affords doctors and dentists a reasonable hope that their skills and hard work will receive a fair reward. No country can afford less.

1 British Medical fournal Supplement, 1970, 4, 40.

Royal Commission on Doctors' and Dentists' Remuneration, 1957-60, Report, Cmnd. 939. London, H.M.S.O., 1960

3 British Medical fournal, 1970, 4, 378

British Medical fournal, 1971, 1, 126

\section{Central Venous Pressure Monitoring}

Monitoring the central venous pressure is widely claimed to be of value in the assessment of requirements of intravenous blood and fluid and in the treatment of cardiogenic and noncardiogenic shock. There are, however, a number of pitfalls in its interpretation which if not appreciated are likely to negate the value of this measurement. ${ }^{1}$

The central venous pressure represents the blood volume as seen from the right side of the heart and is a measure of the 